\title{
Ecoideologias associadas aos movimentos ambientais: contribuições para o campo da educação ambiental
}

\section{Eco-ideologies associated to environmentalism: contributions to environmental education field}

\author{
Ronaldo Gazal Rocha*
}

\begin{abstract}
RESUMO
Diferentes abordagens de desenvolvimento levantam múltiplas possibilidades de interpenetração dos campos natural e social, mediado pela subjetividade humana. Assim sendo, a caracterização de ecoideologias, freqüentemente associadas aos movimentos ecológicos, pode nos fornecer subsídios importantes para a análise de questões ambientais. Na tentativa de discutir os aspectos relacionais dos estudos taxionômicos que vigoram atualmente, consideraremos a origem e as interpenetrações de determinados campos - ou ecoideologias - como forma de compreender o processo de organização dos movimentos ambientalistas nacionais. A partir dos anos 90, fica patente a influência dos movimentos ambientalistas no cenário mundial, especialmente nos campos da política e da economia, o que gera situações de impacto em valores culturais e institucionais. Ainda que a maior parte dos problemas ambientais persista, o estudo das tipificações desses movimentos nos auxilia a avaliar seu potencial transformador, expondo dimensões e conflitos capazes de organizar novas identidades culturais. Tais considerações, longe de serem apresentadas como de caráter hegemônico, buscam contribuir para uma crítica ecológica mais consistente.

Palavras-chave: ecoideologias; movimentos ambientais; educação ambiental; ética.
\end{abstract}

* Mestre em Educação (UFPR). Doutorando do Programa de Pós-Graduação em Educação da UFPR, Área Educação e Trabalho, Linha de Políticas e Gestão da Educação. E-mail: ronaldogazal@ibest.com.br 
ROCHA, R. G. Ecoideologias associadas aos movimentos ambientais...

\begin{abstract}
Different approaches on development raise multiple possibilities of interaction of the natural and social fields, intermediated by the human subjectivity. Therefore, the characterization of eco-ideologies, often associated to ecologic movements, may supply us with important data for the analysis of the environmental issues. In attempting to discuss the relational aspects of the taxonomic studies effective at present, we considered both the origin and the interaction of certain fields - or eco-ideologies - as a way of comprehending the organizational process of the national environmentalist movements. From the 90's, the influence of the environmentalist movements in the worldwide scenario is clear, most specially in the political and economic fields, creating impact situations in cultural and institutional values. Although most of the environmental issues are bound to last, the study of the variations on those movements might help us assessing their changing potential by exposing dimensions and conflicts capable of organizing new cultural identities. Such considerations, far from being presented as of hegemonic character, seek to contributing to a more consistent ecological criticism.
\end{abstract}

Key-words: eco-ideologies; environmentalism; environmental education; ethics.

Um dos primeiros aspectos relevantes acerca das origens do ambientalismo é o fato de ter se estruturado a partir do interesse de alguns elementos das elites americanas ou européias. Para esses, a procura por melhores condições de vida, a preservação da vida selvagem e a vida numa perspectiva "ecológica" de busca por uma harmonização entre o homem e a Natureza, transformou-se em motivos justificados para, muitas vezes, transferirem enormes fortunas em prol da causa ambiental. Associados a essa aristocracia, um grupo de "ecologistas” políticos dedicou-se à organização e estruturação do corpo teórico que acabaria por evoluir em uma tradição às causas pela Natureza.

Idéias preservacionistas podem ser encontradas em documentos oficiais desde o século XVII, sem que, contudo, possa ser possível se referir a noção de movimento (especialmente do ponto de vista social). Entretanto, esse corpo teórico permaneceu por um longo período restrito a determinados círculos sociais, mais como uma tendência intelectual.

Foi ao final dos anos 60 que, em países como os Estados Unidos e Alemanha e, de forma geral, na Europa Ocidental, o "movimento ambientalista de massas, entre as classes populares e com base na opinião pública, (...) então 
se espalhou rapidamente para os quatro cantos do mundo" (CASTELLS, 1999, p. 154). Partindo de movimentos pacifistas, antinucleares e de contracultura, o ambientalismo de recusa ${ }^{1}$ se iniciava com uma diversidade de defensores, o que explicaria historicamente, seu caráter multifacetado.

Partindo de múltiplas representações, o ambientalismo possui internamente lacunas e pontos de conflito entre seus promotores. Entretanto, tais aspectos estão mais freqüentemente relacionados a sua operacionalização (tática, linguagem, prioridades) do que em relação aos seus princípios (defesa do ambiente atrelada aos valores humanos).

Sendo assim, para compreender a influência das ecoideologias associadas aos movimentos ambientalistas no campo da Educação Ambiental, destacamos algumas premissas que se encontram dispersas em seus discursos e que sustentam sua crítica:

1) Relação estreita e ambígua com a ciência e a tecnologia - Muitas instituições ambientalistas contam com cientistas que assessoram a tomada de decisões. Ao mesmo tempo, existe uma enorme desconfiança na possibilidade de desenvolvimento contínuo dos benefícios gerados por essa ciência. Assim, ora se aproximado, ora se afastando do campo científico, o ambientalismo revela um caráter contraditório de dependência e descrença epistemológica;

2) Luta por uma redefinição histórico-social em termos de espaço - A transformação estrutural das sociedades e seu realinhamento com base em novos princípios éticos está entre as prioridades dos ambientalistas. Na era da informação, inúmeras interações sociais se estabelecem sem obrigatoriedade de contigüidade física (televisão, internet, telecomunicações) definindo a maior parte dos processos dominantes de poder, riqueza e informação. Contudo, tais mecanismos não são suficientes para suplantar as experiências que privilegiam a interação social. Ao contrário, os ambientalistas estabelecem estratégias locais que estimulam a participação e envolvimento pessoal

${ }^{1} \mathrm{O}$ termo foi utilizado no início do movimento ambientalista para expressar uma forma de ver o mundo em que não se acreditava ser possível viver ecologicamente na sociedade industrial. Isto implicava distanciamento político e, até mesmo, isolamento social - vida em comunidades alternativas - de seus integrantes que não acreditavam que fosse possível eliminar o individualismo, a competividade e o produtivismo no interior das sociedades capitalistas. O ambientalismo de recusa foi considerado uma visão ingênua, romântica e pouco viável, já que as comunidades alternativas não são solução para o conjunto da humanidade.

${ }^{2}$ Cada subsistema tem sua forma própria de poder. Assim, na economia, a estrutura de poder 
em seus próprios espaços, obrigando a reorientações dos sistemas hegemônicos de poder.

3) Busca por uma nova temporalidade-Alguns aspectos interessantes de análise, no que concerne ao fator tempo, são apresentados por Castells (1999) que considera a possibilidade de existência de três temporalidades: cronológica - característica do modelo industrial de produção; é seqüenciada e disciplinadora do comportamento humano, gerando poucas experiências externas aos padrões de medida institucionalizados; intemporal - partindo-se do paradigma informacional e da sociedade em rede; é aquela evidenciada pelos fenômenos voltados à instantaneidade (guerras e transações financeiras “instantâneas”) ou a descontinuidade aleatória (hipertexto); glacial - implica em um processo evolucionário de longo prazo, que esteja voltada ao equilíbrio dos sistemas naturais (incluindo os humanos), por meio de um projeto duradouro que desenvolva uma “conscientização ecológica” planetária.

4) Criação de uma nova identidade - Talvez uma das tarefas mais difíceis enfrentadas pelos ambientalistas esteja no convencimento dos indivíduos de uma nova identidade para a espécie humana. A cultura humana necessita reconhecer-se como parte integrante de um todo, onde cada homem é apenas mais um elemento da Natureza. Nesse sentido, o desenvolvimento de uma “identidade sócio-biológica” não traz atrelada a si a "negação das culturas históricas”. Ao contrário, "os ecologistas têm profundo respeito pelas culturas populares, e grande apreço pela autenticidade cultural de diversas tradições”.

5) Combate incessante ao nacionalismo do Estado - Se, por definição, o Estado-nação "tende a exercer poder sobre um determinado território”, então, a adoção dessa noção interfere de maneira categórica na sustentabilidade dos ecossistemas, posta a complexa interação reticular que transcende a territórios pré-definidos. Os problemas apresentados às comunidades locais precisam, muitas vezes, de soluções compartilhadas internacionalmente.

Encarado dessa forma, o ambientalismo nos propõe a construção coletiva de uma nova perspectiva de vida na qual se impõe, nas palavras de Castells (1999, p. 160), como uma: 
ROCHA, R. G. Ecoideologias associadas aos movimentos ambientais...

de seus vínculos sociais históricos ou de gênero, ou de seu credo religioso. Contudo, uma vez que a maioria das pessoas não vive no plano cosmológico, e a aceitação de nossa natureza compartilhada com a dos mosquitos ainda impõe certos problemas táticos, a questão decisiva para a influência da nova cultura ecológica consiste em sua capacidade de unir traços de culturas distintas em um hipertexto humano, constituído de diversidade histórica e comunalidade biológica.

Tais considerações, longe de serem apresentadas como de caráter hegemônico, buscam contribuir para uma crítica ecológica mais consistente, sem, contudo, pressupor a existência de um tipo ideal de militante. Somos a única espécie capaz de antever o que o nosso comportamento viabiliza para nosso futuro. O que muitos teóricos procuram é justamente chamar a atenção para as relações estreitas que se estabelecem entre os sistemas, particularmente aqueles alcançados pela ação do homem. Nesse sentido, a análise de Hughes (1989, p. 1-4) nos apresenta um esquema de interconexões de subsistemas, no qual as sociedades estariam organizadas a partir de quatro eixos fundantes: o Estado, a Cultura, a Economia e o Parentesco.

Segundo o modelo (Figura 1), as comunidades estruturam-se a partir

FIGURA 1 - ORIGEM DE ECOIDEOLOGIAS

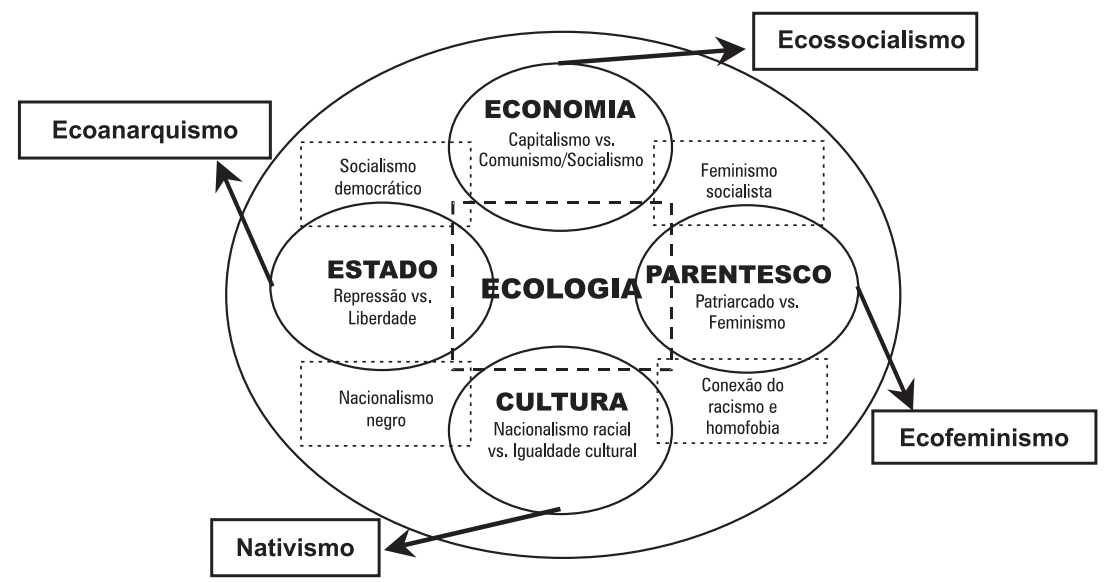

FONTE: HUGHES, 1989, p. 1-4 
da cooperação de suas partes - nação, raça, cultura, linguagem, proximidade geográfica e/ou identidade coletiva - organizadas por um senso coletivo em associação a uma tradição e história comuns, fundamentais para a vida em sociedade. Tal qual na Natureza, as sociedades humanas também se organizariam em sistemas - autônomos, porém extremamente interconexos - capazes de afetarem-se uns aos outros. Cada qual ao seu modo, os subsistemas dariam origem a formas específicas de poder expressas, no interior das sociedades, em restrições religiosas, étnicas ou mesmo de nacionalidade. ${ }^{2}$

Uma vez concebidos esses subsistemas sociais, poderíamos articulá-los aos ideais ecológicos, como forma de compreender quatro ecoideologias específicas. Cada uma revela certo grau de contribuição para a delimitação teórica do campo ambiental. O nativismo acredita na possibilidade de vida harmônica com a Natureza considerando tanto os europeus, como os norte-americanos, culturas alienadas. O ecofeminismo desponta como movimento que procura romper com as relações de submissão da mulher, particularmente nas culturas patriarcais que a associam a uma condição inferior devida a sua "natureza submissa". O ecossocialismo considera que a cooperação e proteção ecológica devem ser priorizadas pela sociedade industrial capitalista de consumo que só “enxerga" a produção pelo lucro. O ecoanarquismo concentra suas atenções nas conseqüências antiecológicas do excesso de centralização governamental e no crescimento do complexo industrial armamentista, propondo a descentralização das estruturas sociais refletidas em sistemas bio-eco-regionais.

Levando em consideração aspectos naturais, econômicos, sociais e políticos, a perspectiva ecológica apresenta-se como um espaço de análise e discussão que busca articular questões desenvolvimentistas e de bem-estar coletivo com o gerenciamento mais racional dos recursos do meio. Para tanto, é necessário que tentemos detectar pontos que nos permitam reconhecer o surgimento e a caracterização de importantes - e discrepantes - movimentos ambientalistas, particularmente no Brasil. Entretanto, a dificuldade de articulação entre campos tão distintos nos obriga a perceber que "este desafio não é somente técnico-científico, mas também político-ideológico, já que um novo padrão de exploração [de recursos materiais e humanos] implicaria transformações na infra-estrutura produtiva, nas relações de poder e na cultura" (SILVA, 1999, p. 1).

estaria em classes; nas relações familiares, recairia sobre o gênero, a preferência sexual ou a idade; na política, apontaria para o poder estatal, os complexos industriais bélicos e a repressão social.

${ }^{3}$ A noção de forças produtivas da natureza foi proposta por Gutelman (1974), citado por Diegues (2000), considerando que processos como a fotossíntese, e noções como a de cadeias tróficas, são elementares para a explicação do funcionamento das sociedades pré-capitalistas e 
Consciente de que toda tipologia érestritiva e, por vezes, reducionista de aspectos significativos, concordamos com DuPuY (1980, p. 23) quando afirma que "as diversas correntes que constituem o movimento ecológico são tão disparatadas que se pode falar [de uma] nebulosa ecológica” que se apresenta através de ações conjuntas e propostas políticas as mais variadas, mas tendo sempre em comum a necessidade de análise e discussão das relações estabelecidas entre a Natureza e a Sociedade. Na visão de Loureiro (2000a, p. 21):

\begin{abstract}
o ambientalismo é (...) concebido como um projeto realista e utópico de múltiplas orientações, que se inscreve na política mundial, simultaneamente, como um posicionamento de apropriação simbólica e material que vai desde o questionamento da sociedade industrial capitalista e das características intrínsecas das leis de mercado, até as iniciativas comportamentais ecologicamente corretas, tendo como eixo analítico o processo de atuação humana no ambiente e a discussão acerca da relação sociedade-natureza, visando a alcançar uma nova base civilizacional.
\end{abstract}

Na tentativa de discutir os aspectos relacionais dos estudos taxionômicos que vigoram atualmente, consideraremos a origem e as interpenetrações de determinados campos - ou ecoideologias - como forma de compreender o processo de organização dos movimentos ambientalistas nacionais e suas implicações no campo da Educação Ambiental.

As ações práticas nos últimos vinte anos dos movimentos internacionais ambientalistas foram estudadas por Castells (1999), que, ao analisar as correntes européias (especialmente na Alemanha) e norte-americanas, do ponto de vista histórico, concluiu que o ambientalismo se apresenta de forma tão diversificada que é "praticamente impossível considerá-lo um único movimento. Todavia, (...) a tese [é] de que é justamente essa dissonância entre teoria e prática que caracteriza o ambientalismo como uma nova forma de movimento social descentralizado, multiforme, orientado à formação de redes e de alto grau de penetração". Sendo assim, destacam-se cinco "correntes ambientalistas" (Quadro 1) que coexistem na prática e, ainda hoje, podem ser identificadas em diferentes discursos e ações.

Com a interferência norte-americana no cenário mundial, vale destacar o trabalho de Hughes (1995) que apresenta um panorama abrangente capaz de caracterizar aspectos ideológicos de "correntes" ambientalistas como forma de identificar ecoideologias que tiveram reflexos (direto ou indireto) sobre o 
ROCHA, R. G. Ecoideologias associadas aos movimentos ambientais...

QUADRO 1 - CARACTERÍSTICAS DOS MOVIMENTOS AMBIENTALISTAS SOCIAIS

\begin{tabular}{|c|c|c|c|}
\hline Tipo / Exemplo & Identidade & Adversário & Objetivo \\
\hline $\begin{array}{l}\text { Preservação da natureza } \\
\text { (Grupo dos Dez, EUA) }\end{array}$ & Amantes da natureza & $\begin{array}{l}\text { Desenvolvimento não- } \\
\text { controlado }\end{array}$ & Vida selvagem \\
\hline $\begin{array}{c}\text { Defesa do próprio espaço } \\
\text { (Not In My Back Yard) }\end{array}$ & Comunidade local & Agentes poluidores & Qualidade de vida/saúde \\
\hline $\begin{array}{c}\text { Ecologia profunda } \\
\text { (Earth first!, ecofeminismo) }\end{array}$ & O ser "verde" & $\begin{array}{c}\text { Industrialismo, tecnocracia } \\
\text { e patriarcalismo }\end{array}$ & Ecotopia \\
\hline $\begin{array}{c}\text { "Salvem o planeta" } \\
(\text { Greenpeace })\end{array}$ & $\begin{array}{l}\text { Internacionalistas na } \\
\text { luta ecológica }\end{array}$ & $\begin{array}{l}\text { Desenvolvimento global } \\
\text { desenfreado }\end{array}$ & Sustentabilidade \\
\hline $\begin{array}{c}\text { "Política verde" } \\
\text { (Die Grünen) }\end{array}$ & $\begin{array}{l}\text { Cidadãos preocupados } \\
\text { com meio ambiente }\end{array}$ & Estabelecimento político & Oposição ao poder \\
\hline
\end{tabular}

FONTE: ADAPTAÇÃO DE CASTELLS (1999, p. 143).

movimento ecológico brasileiro.

\section{Ecocapitalismo ou capitalismo ecológico}

Para a maioria das pessoas a questão ambiental é mal compreendida, isto é, repleta de imprecisões ou reducionismos que, por vezes, passa até a ser encarada como mais um modismo, de mais uma "simples" campanha publicitária muito bem organizada. Para esses indivíduos, o desenvolvimento científico sempre proporcionará as condições necessárias para a resolução de nossos problemas ecológicos. Os "ambientalistas” libertários acreditam que descobriram uma forma de solucionar o problema das "externalidades" ambientais. O problema ambiental está relacionado à propriedade dos bens naturais, isto é, a "privatização" do ar, da água, do solo, supostamente proporcionaria o "direito" de poluir e, desse modo, a compra e venda desses produtos equilibraria perfeitamente os interesses industriais e ambientais.

\section{Conservacionismo}

Grupos “ambientalistas" anteriores à década de 60, tal qual o Sierra Club, principalmente formados por caçadores e adeptos da vida ao ar livre (outdoorsmen) que se demonstravam preocupados com a "preservação da vida selvagem". Os conservacionistas estabeleceram parques nacionais e privilegiaram a manutenção dos "recursos vitais americanos". Geralmente são “colaboradores” republicanos. 


\section{Ambientalismo}

O termo foi empregado como uma postura modista que refletia a política liberal dos democratas do Sierra Club, do Conselho de Defesa dos Recursos Naturais (NRDC/USA - National Resources Defence Council), dentre outros. São orientados por atividades legais e de pressão (lobbying) que incluem ecocapitalistas e conservacionistas.

\section{Ecopopulismo}

A maioria dos ativistas ecológicos nos EUA não se autodenomina "ambientalistas" ou "verdes". São, na grande maioria, grupos pouco articulados - embora existam representações significativas como o Citizens Clearinghouse on Hazardous Wastes - formados por mães e trabalhadores associados em grupos de resistência e oposição aos efeitos da poluição (contra os filhos doentes e trabalhadores prejudicados). Como grupos “não-ideológicos”, são marcados por uma visão antiassociativa, desde que sejam diretamente confrontados com a incompatibilidade do lucro frente às necessidades humanas. Também são conhecidos como Não no meu quintal (Not In My Back Yard - NIMBY)

\section{"Verdes"}

O termo passou a ser mais amplamente utilizado após a ascensão do Partido Verde na Alemanha Ocidental, posteriormente emergindo por toda a Europa e Terceiro Mundo. Aqueles que se dizem "verdes" defendem uma pluralidade de questões, independentemente da ação política do Partido Verde, alcançando desde os "verdes-verdes" (green greens), profundamente compelidos a ações ecológicas, passando pelos anarquistas revolucionários (fundi greens), que vêem na política eleitoral somente propaganda, até os "verdes-vermelhos" (red greens), que acreditam que a política verde recoloca o marxismo como uma ideologia radical de compreensão do mundo, unificando socialismo, feminismo, movimentos anti-racistas, dentre outros.

\section{Ecologia profunda}

É uma filosofia anti-racionalista e difícil de se definir com precisão. A questão central da ecologia profunda (Deep Ecology) é reverter o atual quadro antropocêntrico para outro biocêntrico. O biocentrismo vê a "Natureza" como um bem em si mesma, e de que todas as espécies têm igual importância. São adeptos de uma redução drástica na população humana, na intervenção 
humana na Natureza e no atual modo de vida humano. Argumentam que os pré-industriais estavam/estão em harmonia com a ordem natural.

Dentre os adeptos da ecologia profunda sobrepõem-se verdes "new age” que procuram por uma nova forma de vida voltada à auto-realização e espiritualização e o grupo Earth First!, considerados freqüentemente como anarquistas, versão ecoguerrilha da Ecologia profunda. Ativistas Earth First! passam grande parte de seu tempo em áreas selvagens e propõem que a maior parte do território americano deveria retornar a ser ecossistemas naturais. Depois que vários de seus líderes se expressaram de forma racista, machista e misantrôpica, o Earth First! passou a ser atacada pela esquerda.

\section{Ecomarxismo}

O movimento do ecomarxismo surge a partir do marxismo clássico, como crítica à visão estática do mundo natural concebida por Marx. Os ecomarxistas argumentam que Marx considera a natureza "apenas em virtude da ação transformadora do homem, por meio do processo de trabalho, proporcionando-lhe as condições naturais desse trabalho e o arsenal dos meios de subsistência" (DIEGUES, 2000, p. 47). Dessa forma, a natureza não é concebida como uma força em si mesma, mas como mero objeto de consumo, simples mercadoria, ou meio de produção.

Apesar de estarem muito aproximados da tendência marxista clássica, apresentando os problemas sociais como oriundos da forma capitalista de produção, os adeptos ao ecomarxismo se baseiam no conceito de forças produtivas da natureza, ${ }^{3}$ em oposição à noção de forças produtivas históricas. Argumentam que os desastres ecológicos, nos regimes comunistas, resultaram de sua opção por uma "tecnologia capitalista".

\section{Ecofeminismo}

Tendem a ser "new age” ou "deep ecology”, embora mais radicais, formando uma crítica não-linear a toda forma de discriminação e inferiorização da mulher. Sua principal crítica está contra a sociedade patriarcal que associa a mulher a sua Natureza inferior. Esse movimento ecológico propõe alterar a

capitalistas.

${ }^{4}$ VIOLA, E. O movimento ambientalista no Brasil (1971-1991): da denúncia e conscientização pública para a institucionalização e o desenvolvimento sustentável. In: GOLDENBERG, M. (Org.) Ecologia, ciência e política. Rio de Janeiro: Revan, 1992. 
visão patriarcal vigente no mundo, colocando a mulher em lugar de igualdade de condições com os homens.

\section{Biorregionalismo ou ecologia cultural}

Acreditam que as sociedades humanas deveriam ser descentralizadas, e as fronteiras políticas deveriam refletir as localizações biogeográficas. Tendem a ser "new age" ou "deep ecology" subculturados e desinteressados do ativismo político.

\section{Ecologia social}

O termo, proposto por Murray Bookchin (1921-), coloca-se como filosofia coerente do anarquismo ecológico. Admite que a humanidade não é vista como elemento isolado da Natureza, mas sim como um saber natural de si mesmo. Uma hierarquia não-natural surgiu na sociedade, causando alienação dos indivíduos humanos. O caminho para salvar os ecossistemas é acabar com toda forma de hierarquização humana (incluindo as de raças, sexo e classes sociais), o que nos faria retornar à sanidade ecológica natural. São anticapitalistas que, nas palavras de Diegues (2000, p. 45), “criticam a noção de Estado e propõem uma sociedade mais democrática, descentralizada e baseada na propriedade comunal de produção". A Ecologia social ficou confinada nas décadas de 60 e 70 a pequenos círculos, emergindo nos anos 80 como radicais verdes, formando a rede internacional dos "Left Green".

\section{Ecossocialismo}

Acreditam que o socialismo democrático é a condição necessária para a proteção ecológica, mas não a única suficiente. Apresentam as políticas ecológicas dos governos socialistas (nordeste europeu) como vitórias conseguidas contra as políticas corporativistas. Contrastam suas vitórias com a derrocada do comunismo, ou das sociedades tecnoburocratizadas. Um de seus mais proeminentes defensores é Barry Commoner (1915-), que argumenta que a regulação tem sido ineficiente na defesa do meio ambiente, e que o controle democrático da economia deveria ser estendido. Os ecossocialistas rejeitam a idéia de que o socialismo por si mesmo será capaz de salvar os ecossistemas; acreditam que somente a coalizão entre a "esquerda democrática”, incluindo os grupos ecológicos e outros movimentos sociais, poderia estabelecer uma sociedade justa e sustentável. Acreditam que as instituições transnacionais deveriam implementar um programa mundial de auxílio do Primeiro Mundo ao desenvolvimento dos 
países do Terceiro Mundo.

Para fins de orientação e delimitação das tendências do ambientalismo no Brasil, as propostas de classificação revelam a interferência de sua origem multifacetada.

Segundo Viola, ${ }^{4}$ citado por Leis e D'Amato (1998, p. 77), as “abordagens teóricas mais tradicionais" vislumbram o ambientalismo sob um dos três aspectos: 1) como grupo de pressão ou interesse; 2) como movimento social; ou 3) como movimento histórico.

No primeiro caso, o ambientalismo está perfeitamente integrado ao sistema político, sem preocupações contestatórias, mas voltado para a solução de situações específicas definidas. É o enfoque mais comumente encontrado nos EUA, partindo das classes média e alta da sociedade, sendo, portanto, considerado elitista.

A segunda abordagem concebe o ambientalismo como uma maneira alternativa à ordem em vigor, como um "novo" movimento social, porém contextualizado com o aspecto normativo, tal qual nos movimentos pacifistas ou feministas. Esse enfoque é mais comumente observado na Europa Ocidental, onde as vertentes mais extremadas do ambientalismo estão próximas ou associadas aos partidos verdes.

A terceira perspectiva, minoritária atualmente, concebe o ambientalismo como resposta às aspirações de diferentes setores sociais contra o padrão civilizacional vigente. Portanto, é encarado mais como um movimento histórico do que meramente social. Caracteriza-se por seus aspectos multissetorial, pluriclassista e global que, em síntese, revela seu caráter plural por "eixos não excludentes em suas interfaces e fundamentação teórica”. ${ }^{5}$

Essa espécie de tipologia reforça uma percepção abstratamente idealizada que conseqüentemente desvela o principal obstáculo ao multissetorialismo, ou seja, o particularismo. Entretanto, as tentativas de superação dessa dificuldade não se demonstraram efetivas, muitas vezes levando ou ao descrédito de determinados setores devido à falta de sustentação teórica e capacidade de discussão de seus processos internos ou, nas palavras de Boeira (2002, p. 2), ao "globalismo acrítico e desmobilizador". Ambos os posicionamentos denotam, por vezes, argumentos falaciosos, excludentes e restritivos que privilegiam noções superficiais (como em desenvolvimento sustentável) sem

${ }^{5}$ Verificar o estudo de Loureiro (2000, p. 23) e Boeira (2002, p. 2).

${ }^{6}$ LO VUOLO, R. Uma nueva oscuridad? Estado de Bienestar, crisis de integración social y democracia. In: LO VUOLO, R.; BARBEITO, A. La nueva oscuridad de la política social. Del Estado populista al neoconservador. Buenos Aires: CIEPP/Minõ y Dávila, 1993.

${ }^{7}$ Segundo Lo Vuolo, o princípio do mérito "sustenta que os velhos esquemas institucionais 
a devida análise crítica.

A possibilidade de se imaginar alguns "caminhos" poderia nos reportar ainda às observações da obra de Leis e D’Amato (1998) no sentido de que o ambientalismo pode ser considerado como um esquema relacional entre a Natureza e a sociedade, articulados a valores capazes de orientar e organizar as relações humanas: os princípios de igualdade e de hierarquia (Quadro 2).

Apesar de essa classificação ser relativamente comum na literatura ambientalista, ela é passível de crítica, uma vez que

(...) se pauta em valores cristãos e numa ética da fraternidade e do sacrifício, igualitária entre a humanidade e demais seres da natureza. Isto é pouco defensável para efeito de análise do processo de formação do

QUADRO 2 - VERTENTES DA ÉTICA ECOLÓGICA

\begin{tabular}{|c|c|c|c|c|c|}
\hline \multirow{6}{*}{ 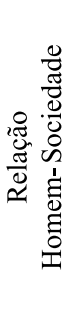 } & & \multicolumn{4}{|c|}{ Relação Homem-Natureza } \\
\hline & & \multicolumn{2}{|c|}{$\begin{array}{c}\text { Princípio Hierárquico: } \\
\text { Antropocentrismo }\end{array}$} & \multicolumn{2}{|c|}{$\begin{array}{c}\text { Princípio Igualitário: } \\
\text { Biocentrismo }\end{array}$} \\
\hline & Princípio Igualitário: & Beta & & \multirow{2}{*}{\multicolumn{2}{|c|}{ Delta }} \\
\hline & Comunitarismo e/ou Coletivismo & & \multirow{2}{*}{\multicolumn{2}{|c|}{ Ômega }} & \\
\hline & Princípio Hierárquico: & \multirow{2}{*}{ Alfa } & & & \multirow{2}{*}{ Gama } \\
\hline & Individualismo & & & & \\
\hline
\end{tabular}

FONTE: LEIS \& D’AMATO (1998, p. 86).

ambientalismo, pois permite se dizer que toda tendência que não siga este caminho, idealmente concebido, de Alfa para Ômega, estará destinada ao fracasso. O sentido de construção de hegemonia em uma sociedade contraditória, de unidade na diversidade, fica inviabilizado neste tipo de classificação (...). (LOUREIRO, 2000b, p. 25)

Outra abordagem possível é a histórica que nos permite perceber que os movimentos ambientalistas são diretamente influenciados pelos aspectos sociais, políticos e econômicos, além da forma como percebemos a Natureza. A partir do desenvolvimento de uma sensibilidade "ecológica" e de um processo de conscientização, Ramos (1996, p. 62) define, grosso modo, três tendências 
ROCHA, R. G. Ecoideologias associadas aos movimentos ambientais...

dos movimentos ecológicos:

\section{Naturalista}

O movimento ecológico naturalista teve seu marco inicial no final da década de 60 e estendeu-se por toda a década de 70, podendo ser caracterizado pela influência direta dos ideais libertários defendidos por intelectuais como Herbert Marcuse (1898-1979), Rene Dumont (1904-2001), Ivan Illich (1926) e pela contracultura norte-americana. Ficou marcado por sua ecologia utópica (ecotopia) e por atitudes anti-sociais típicas do ambientalismo de recusa. Essa "corrente" considerava a Natureza "como um santuário ou como objeto de deleite estético" que devia ser preservado, mas foi apropriada pela lógica capitalista transformando o "verde" em simples objeto de consumo, em não mais do que uma mera mercadoria.

\section{Institucional}

Pode-se dizer que o movimento ecológico nos anos 70, além do posicionamento anteriormente descrito, também foi institucionalizado. A partir da divulgação de relatórios e publicações de resultados das discussões acerca da questão ambiental, são sugeridos posicionamentos e iniciativas pelas entidades internacionais de países industrializados para contornar a crise ecológica. Considera-se que a existência desse movimento "oficial", eminentemente técnico, na verdade pretendia - e pretende - ajustar o ambientalismo ao atual modelo de produção e seus problemas internos.

\section{Político}

Estando intimamente relacionado à concepção dialética de Natureza, o movimento ecológico político concentra a maior parte da ecologia de "esquerda” que considera primordial não "o meio ambiente em si mesmo, mas o meio enquanto realidade profundamente afetada pela lógica produtivista da sociedade industrial contemporânea”. A postura política desse movimento visava aprofundar as discussões sobre a crise ecológica apresentando posições críticas frente aos movimentos ecológicos supostamente "apolíticos" ou aqueles que desejavam a simples acomodação ao sistema produtivo vigente. O movimento também ficou conhecido como Ecologia Política por buscar integrar a sociedade à Natureza, levando em consideração a maneira como "a sociedade está política e economicamente organizada”.

Diante de tamanha diversidade de classificações, que levam em consi- 
deração diferentes critérios, fica evidente que para compreender as inúmeras ecoideologias geradas na intersecção entre os campos da Ecologia e das Ciências Sociais, é fundamental expor e confrontar as diferentes concepções usualmente associadas aos movimentos ecológicos.

A tipificação dessas representações, ainda que traga consigo inúmeros problemas, nos fornece rico material de análise para as práticas e discursos "ecológicos" vigentes. Ao mesmo tempo em que essa plêiade revela novas formas de organização, abre espaços para a dinamização e transformação dos processos de intermediação política que assegurarão uma maior participação social na gestão das questões ambientais.

Os movimentos ambientalistas podem ser mais bem compreendidos como resposta da sociedade civil à crescente interferência antrópica na Natureza. Relativamente recente, trazem consigo uma enorme complexidade de formas de organização e de interação política que se expressam por práticas divergentes. Esse aspecto poderia levantar suspeitas sobre a eficácia dos movimentos, como forma organizada de luta, embora "os novos movimentos ambientalistas [mostrem] um maior grau de flexibilidade, adaptabilidade, [e] capacidade de resposta a possibilidades de radicalizar suas demandas” (LEFF, 2001, p. 151). Tais características conferem uma forma de ação e um comportamento político que tem tido destacado papel ante a incapacidade de resposta das tradicionais organizações politicamente institucionalizadas, partidos políticos e, até mesmo, sindicatos.

Nos países do Terceiro Mundo, os movimentos ambientalistas têm estado, com freqüência, associados às discussões relacionadas ao modelo civilizatório dominante, determinado pela problemática socioeconômica. É nesse sentido que a educação deve ser ressaltada como de caráter crucial para a transformação das sociedades, particularmente viabilizando o desenvolvimento de uma nova ética, pautada em valores distintos daqueles considerados norteadores de uma sociedade de consumo e produtora de mercadoria. Para tanto, se pudermos falar de um "profissional” de Educação Ambiental, este deve privilegiar múltiplas dimensões, dentre as quais se destacariam a ambiental, encarada tecnicamente como forma de administrar a relação homem-natureza, e a social, concebida como forma crítica de desenvolvimento dessa nova ética. É nesse sentido que as propostas de Educação Ambiental se inserem como importantes instrumentos transformadores da realidade, uma vez que seus princípios, seus objetivos e suas práticas são permeados por uma ética capaz de produzir alterações significativas de comportamento nos indivíduos, levando a novos hábitos e atitudes, pautados em valores que estreitam as relações entre os homens e os colocam como parte integrante do meio.

Apesar dessas possibilidades, não podemos esquecer que o momento 
atual em que vivemos - uma era de "globalização" - interfere não somente nas relações econômicas, mas também se reflete nas decisões políticas, nas relações jurídicas, na cultura e, evidentemente, na educação. A criação de uma nova ordem mundial, especialmente após o fim da guerra fria, acirrou ainda mais um modelo de exclusão social e de marginalização de determinados setores da sociedade. A aparente normalidade do processo de globalização baseia-se "[n]o desenvolvimento contemporâneo das sociedades 'competitivas'”, que passam a ser reguladas pelo que Lo Vuolo ${ }^{6}$ apud Gentili (1998, p. 234) designa como princípio do mérito, ${ }^{7}$ que, em última análise, funciona como uma "norma de desigualdade" que "consagra a divisão social dualizada, ao mesmo tempo em que a transforma em uma meta a ser conquistada".

Assim sendo, a Educação Ambiental pressupõem que a educação tradicional foi - e é - incapaz de responder a todos os desejos e necessidades dos mais diferentes integrantes da sociedade, especialmente porque estimula a competitividade irracional. Deparamo-nos atualmente com um modelo de educação que, no mínimo, é questionável em dois aspectos: primeiro, no sentido de propiciar o desenvolvimento do senso crítico, compreendido como forma de pensamento que auxilia e permite a distinção entre diferentes discursos e a forma sob as quais se apresentam; e segundo, no que diz respeito à formação humana, encarada como possibilidade de viabilizar procedimentos capazes de permitir o reconhecimento de situações de conflito e de orientar a tomada de decisões voltada à participação crítica na sociedade.

Portanto, precisamos nos mobilizar para que as múltiplas experiências dos diferentes integrantes da sociedade possam ser compartilhadas, transformando-se em fonte inesgotável de novos saberes. A educação e os movimentos ambientalistas, assim como outras formas de interação social, evoluem com base na sociedade que lhe produz. Criatividade, conhecimento e participação podem ser instrumentos, mais do que importantes, cruciais para o desenvolvimento de uma nova ética mundial, de fato, globalizada. Entretanto, Brügger (1999, p. 61-2) chama a atenção para a dificuldade de tal tarefa, se não reco-

premiavam os ineficientes, enquanto os novos, ao aumentar a dependência de cada um do valor de troca no mercado de sua capacidade individual, farão com que as retribuições sejam de acordo com sua maior ou menor eficiência como participante do sistema de trabalho social”. 
ROCHA, R. G. Ecoideologias associadas aos movimentos ambientais...

nhecermos sua subjetividade implícita.

\begin{abstract}
A falta de ética não se restringe a cada indivíduo mas faz parte de uma "lógica" que abrange toda a sociedade. Uma conseqüência disso é que diversas profissões mal remuneradas são freqüentemente aquelas potencialmente mais importantes do ponto de vista social. E o inverso é muitas vezes verdadeiro. Parece uma incoerência mas não é. O sistema coerentemente paga melhor a quem ajuda a sua perpetuação. Isso é lógico e ao mesmo tempo ideológico.
\end{abstract}

Então, considerando a proposta de Loureiro (1999, p.18), concebemos a Educação Ambiental como “(...) um processo educativo de construção da cidadania plena e planetária, que visa à qualidade de vida dos envolvidos e à consolidação de uma ética ecológica”. Somente assim poderemos inserir o "elemento educativo do novo paradigma ecológico", propondo a "rediscussão da presença humana na natureza, indo além dos aspectos naturais da problemática ambiental".

Diante do exposto, é fato que diferentes concepções de educação, meio ambiente e mesmo de desenvolvimento podem - e devem - coexistir. Portanto, o que pensam e como agem os "profissionais" voltados para uma prática ambiental (ecológica) é diretamente dependente e influenciado por noções discutidas e trabalhadas nos movimentos ambientalistas. Longe de buscar uma padronização limitadora, a apreciação de compreensões diversas acaba por contribuir para a reflexão crítica e para o esclarecimento de questões e, conseqüentemente, na evolução do atual quadro onde se encontram inseridos os educadores ambientais. Assim sendo, o estudo do ideário dos "profissionais” de Educação Ambiental, bem como suas formas de interpenetração e ação nos diferentes setores da sociedade transformam-se numa temática rica e profunda de análise que deve, primeiramente, retomar as representações de educação, ambiente e realidade social que esses agentes de transformação trazem consigo.

\title{
REFERÊNCIAS
}


ROCHA, R. G. Ecoideologias associadas aos movimentos ambientais...

BOEIRA, S. L. Enfoques teóricos sobre o ambientalismo. In: Verba Volant do Pensamento Ecológico. Disponível em: htpp://hps.infolink.com.Br/ peco/main.htm. Acesso em: 05 jan. 2002.

BRÜGGER, P. Educação ou adestramento ambiental? 2. ed. Florianópolis: Letras Contemporâneas, 1999.

CASTELLS, M. O poder da identidade. v. II, São Paulo: Paz e Terra, 1999.

DIEGUES, A. C. S. O mito moderno da natureza intocada. 3. ed. São Paulo: Hucitec/USP, 2000.

DUPUY, J-P. Introdução à crítica da ecologia política. Rio de Janeiro: Civilização Brasileira, 1980.

GENTILI, P. Adeus à escola pública: a desordem neoliberal, a violência do mercado e o destino da educação das maiorias. In: GENTILI, P. et al. (Orgs.). Pedagogia da exclusão: crítica ao neoliberalismo em educação. 4. ed. Petrópolis: Vozes, 1998.

HUGHES, J. Democratic socialism and green politics. Grey City Journal, 1989. Disponível em: http://dsausa.org/archieve/ESR/JDSEco.html. Acesso em: 15 jan. 2002.

. A quick guide to eco-ideologies. Eco-socialist Review, 1995. Disponível em: http://dsausa.org/archieve/ESR/Ecoldeas.html. Acesso em: 23 mar. 2002.

LEFF, E. Epistemologia ambiental. São Paulo: Cortez, 2001.

LEIS H. R.; D’AMATO J. L. O ambientalismo como movimento vital: análise de suas dimensões histórica, ética e vivencial. In: CAVALCANTI, C. et al. Desenvolvimento e natureza: estudos para uma sociedade sustentável. 2. ed. São Paulo: Cortez, 1998. p. 77-103.

LOUREIRO, C. F. B. A assembléia permanente de entidades em defesa do meio ambiente-RJ e o pensamento de esquerda: análise crítica do coletivo organizado a partir do depoimento de suas históricas lideranças estaduais. Rio de Janeiro, 2000a. 285 f. Tese (Doutorado em Serviço Social) - Escola de Serviço Social, Universidade Federal de Rio de Janeiro.

. Considerações sobre o conceito de educação ambiental. Teoria e Prática da Educação, Maringá, v. 2, n. 3, set. 1999.

Ética e cidadania: conceitos básicos para a transversalidade em educação ambiental. In: MATA, S. F. et al. (Orgs.). Educação ambiental: transversalidade em questão. Rio de Janeiro: MZ, 2000b.

RAMOS, E. C. Educação ambiental: evolução histórica, implicações teóricas e sociais. Uma avaliação crítica. Curitiba, 1996. Dissertação (Mestrado em Educação) - Setor de Educação, Universidade Federal do Paraná.

SILVA, C. A. da. Conservación de la naturaleza versus desarollo económico: cuestiones 
ROCHA, R. G. Ecoideologias associadas aos movimentos ambientais...

para el debate a la escala mundial y de Brasil. Scripta Nova, Universidad de Barcelona, v. 14, n. 45, p.1-9, ago.1999. Disponível em: http://www.ub.es/geocrits/n-45-14.htm. Acesso em: 22 abr. 2002.

Texto recebido em 16 ago.2005

Texto aprovado em 17 out.2005 